\title{
SOLDIER HEALTH MONITORING AND POSITION TRACKING SYSTEM
}

\author{
V. L. Satyanarayana, \\ Assistant Professor, Department of ECE \\ P.S.C.M.R College of Engineering and \\ Technology Vijayawada, India.
}

\begin{abstract}
The chief subject of this task is wellbeing checking and following device for fighters. The Soldier Health and Position Tracking System grants the military to follow the current day GPS job of a warrior and furthermore evaluations the wellness fame including outline temperature and heartbeat of the trooper. This measurement may be transmitted to the oversee room through GPS and GSM. This device obliges little wearable physiological equipment, sensors, transmission modules. Subsequently, with utilizing the hardware, it's miles doable to authorize a low expense component to watch the important human life in the war zone.

The GPS modem sends the range and longitude position with link pattern with the help of that navy can track the modern role of the soldier. The system could be very helpful for getting fitness popularity facts of soldier and imparting them instant assist.
\end{abstract}

Keywords: Arduino UNO Board, GPS module, GSM SIM800L, LM35 Temperature sensor, Pulse rate sensor, Vibrator.

\section{INTRODUCTION}

The country's security is observed and spared by military, armed force and flying corps. The basic and imperative position is of squaddies who penance them ways of life for their nation. There are numerous worries concerning the wellbeing of the warrior. Officers entering the adversary lines regularly lose their carries on with because of loss of network, it's far basic for the army installation station to respected the area notwithstanding wellness fame of all infantrymen. India has just lost such a ton of fighters in war-fields as there has been no appropriate wellbeing reinforcement and network between the warriors on the war-fields and the officials at the army installation stations. As of late

\author{
R V S K Vyshnavi, Sk Nagoor Basha, \\ Manoja Sagiri, L Siva Sai Prasad \\ Department of ECE \\ P.S.C.M.R College of Engineering and \\ Technology Vijayawada, India.
}

on 29 September 2016, a naval force difference among India and Pakistan started, Indian infantrymen played out a careful negative mark against activist discharge cushions over the street of control in Pakistani-controlled Azad Kashmir, and dispensed "tremendous causalities".

Indian squaddies are specifically perceived for their fearlessness, despite scant ammo and security measures, they've numerous victories to their credits. All ought to be really stressed over the security of the infantrymen, so we have resolved to fabricate a test which will accurately keep up a beware of the wellness popularity of the trooper, and his exact territory to furnish him with vital logical medicines as quickly as time permits. Officer's following is done the utilization of GPS and GSM is utilized to give remote verbal trade framework. For following the wellness boundaries of officer we are the utilization of bio logical sensors alongside temperature sensor and heart beat sensor.

\section{PROPOSED METHOD}

In the wake of thinking about the above innovation, the checking of trooper a route between warrior to the fighter, for example, understanding their speed, separation, tallness notwithstanding wellbeing notoriety of them during the war, which empowers the military individual to plot the war procedures. The base station gets an area of a trooper from GPS. The base station can get admission to the forefront status of the fighter that is shown on the telephone with the assistance of GSM and subsequently reasonable activities might be found. By utilizing vibrator, the fighter can know the approaching message from the control room.

\section{HARDWARE REQUIREM ENTS}

The following are the hardware necessities for the system 


\section{International Journal of Engineering Applied Sciences and Technology, 2020 \\ Vol. 5, Issue 2, ISSN No. 2455-2143, Pages 645-649 \\ Published Online June 2020 in IJEAST (http://www.ijeast.com)}

\section{a. Pulse Sensor:}

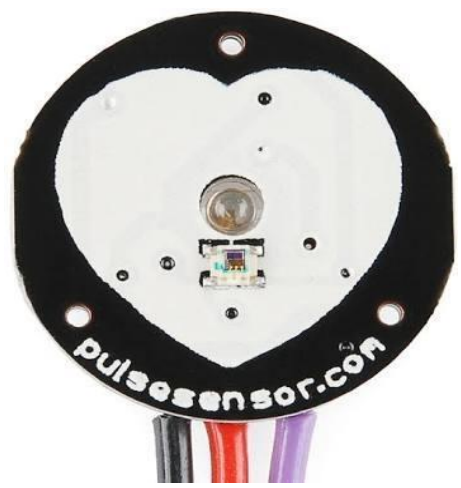

Fig: Pulse Rate Sensor

The sensor applied in this endeavor is beat sensorSEN-11574. Heart charge measurements can be surely gainful for making sense of the wellness acknowledgment of an individual. The beat sensor amped is an attachment and play heart charge sensor for Arduino. It essentially joins a smooth optical heart accuse sensor of enhancement and commotion wiping out hardware making it quick and simple to get dependable heartbeat readings. It tastes vitality with only $4 \mathrm{~mA}$ present day draw at $5 \mathrm{~V}$. To utilize it unquestionably cut the heart beat sensor to ear cartilage or fingertip.

\section{b. Temperature Sensor}

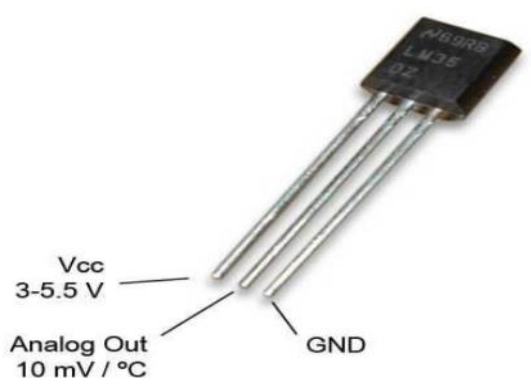

Fig: Temperature sensor

This assortment is exactness incorporated circuit temperature contraptions with a yield voltage straightly corresponding to the centigrade temperature. The position over straight temperature sensor aligned in Kelvin or Centigrade, in light of the fact that the client isn't required to take away a major steady voltage from the yield to secure helpful centigrade scaling. To find the wellbeing status of the trooper base station should know the edge temperature and heartbeat charge of the fighter. So we are the use of LM35 outline biosensor as it's miles an easy temperature sensor and it does now not require signal molding. The LM35 creates a superior yield voltage than thermocouples and probably won't necessitate that the yield voltage is intensified. As the temperature blast over the predefined value the GSM module will on the double alarm the Base station and as an outcome will now not hang tight for heart pulsates to leave the regular range.

\section{c. Power Supply}

The most vital section in each digital circuit is that the facility delivers. For the proper working of all components, an unaltered strength delivery is required. The delivery should be able to provide the specified power for every component. At the same time, the protection from over-voltage ought to be there. The important step inside the designing of any device is to style the power delivery required for that gadget. The designing of energy delivers calls for the whole cutting-edge that the machine sinks from the supply and for that reason the voltage rating required for the various components. all through this mission artwork $5 \mathrm{~V}$ constant strength deliver for GPS, GSM Module is used.

\section{d. Arduino Board}

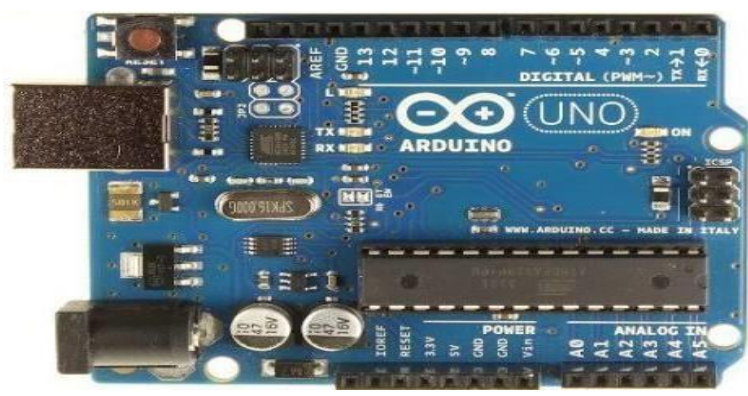

Fig: Arduino Board

Microcontrollers vicinity unit one amongst the most elements in any embedded system. It is probably a bit portable laptop on one included circuit containing a processor core, memory and programmable input/output peripherals. Microcontrollers upload line with this machine written within its software program memory. The most critical use of those single chip computer systems is in computerized responding devices. The feature of this aspect is to build up the records regarding heartbeat of the soldier, 
atmospherically temperature and region of the soldier in every minute. Then it sends this reality to the bottom unit. The ATmega328 is accomplice degree divorced -chip microcontroller created by the usage of AT mega in the mega AVR family. The tool operates among one.8-five. five volts. The device achieves turnout approaching one unit consistent with Mc.

\section{e. GPS Modem}

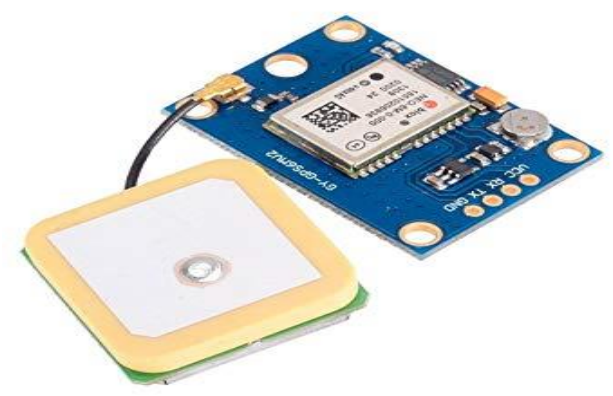

Fig: GPS Neo 6M V

The GPS (Global Positioning System) can be a space-based commonly international navigation satellite gadget that has reliable segment partner degreed time statistics all told weather and within the least times and wherever on or close to the world whereas and wherever there is an unobstructed line of sight to four or larger GPS satellites.

\section{f. GSM Modem}

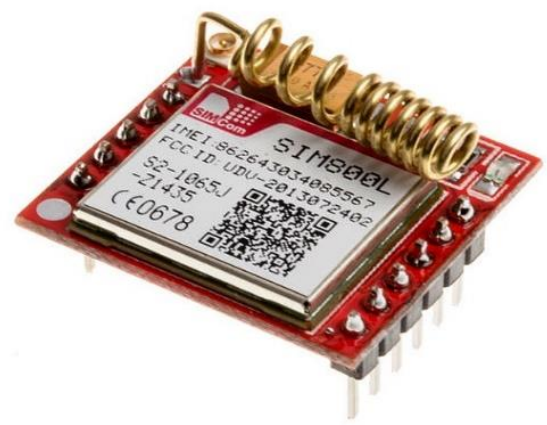

Fig: GSM Sim800L

SIM800L GSM/GPRS module could be a miniature GSM electronic equipment, which can be enclosed into an amazing vary of IoT comes. You'll be able to use this module to perform almost something a popular cell cellular telephone can; SMS matter content material messages, build or get hold of cellphone calls, connecting to net through GPRS, TCP/IP, and more. To high it off, the module supports quad-band GSM/GPRS network, which means that it works just about every place in the globe.

\section{g. Vibrator}

In this project, vibrator is employed to sense the soldier once the message is received from the room. once the settled person sends the knowledge to manage space but the room sends the message WHO area unit with reference to the settled soldier. once the message is received the vibrator mechanically vibrates indicating that the message is received from room.

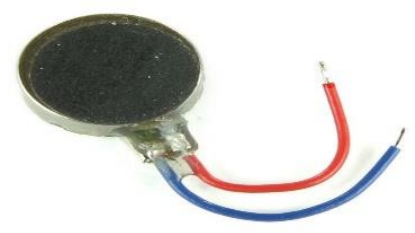

Fig: Vibrator

\section{Block Diagram}

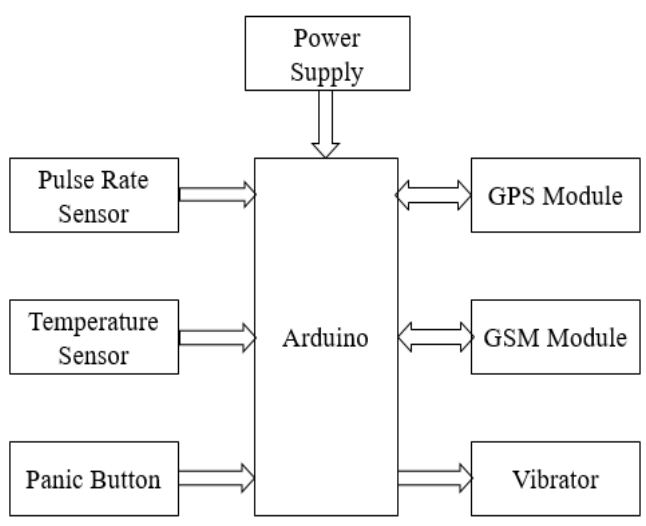

\section{PHYSIOLOGICAL ALERTS AND BIOSENSORS}

With today's advances in generation, diverse wearable sensors are advanced for the monitoring of human physiological parameters. the numerous sensing era are available, which can be blanketed as a part of fitness monitoring system, collectively with their corresponding measured physiological sign. The measurement of the ones vital bio signs and their next processing for function extraction, purpose collection of real time accumulate parameter that allows you to supply an ordinary estimation of health situation at any real time There are a number of clinical 


\section{International Journal of Engineering Applied Sciences and Technology, 2020 \\ Vol. 5, Issue 2, ISSN No. 2455-2143, Pages 645-649 \\ Published Online June 2020 in IJEAST (http://www.ijeast.com)}

parameters of soldier so that you can be monitored, like ECG, EEG, Brain Mapping, etc. But those require complex circuitry and superior clinical centers and as an end result they cannot be carried around via the soldier. The complete tool would discover yourself cumbersome for the soldier.

\section{SOFTWARE REQUIREMENTS}

\section{- Arduino IDE}

\section{RESULT AND CULMINATION}

The end result is proven in the underneath figure. A message is deliver at the registered variety confirming about GSM and GPS configuration. Later due to the fact the everyday frame parameters deviate an alert message is ship to base station alongside with the proper place of the soldier and therefore the close by soldier can understand the real effected soldier by using vibrator when the message is received from room. Following conclusion are often retrieved from above implementation are:

- Modules used are smaller in size and also lightweight in order that they will be carried around.

- So throughout this manner concept of tracking and navigation system is extremely useful for infantrymen while they're on military field at some stage in war. And moreover for base station in order that you'll get real-time view of soldier.

The below figure shows the message received to base station. By this message, the base station alerts all GPS which are with the soldiers and calculated the distance between the affected soldier. If the difference between the affected soldier and normal soldier is less when compared to others, then the base station sends the alert message to soldier. This means the vibrator vibrates the kit. So that the soldier can identify the person who is affected nearby him.

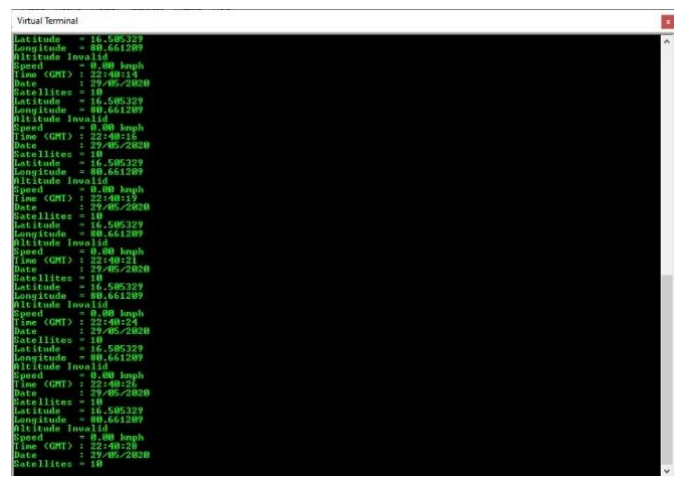

Fig: Message displayed in Control Room

\section{FUTURE SCOPE}

There is usually danger to improve any machine as research \& development is an infinite process. The following measurements can be accomplished in future:

- IC HM2007 may be used to understand the voice samples of the soldier, for higher safety purpose.

- A Camera may be equipped into the machine that allows you to allow the lowest station to get a real time view of the battlefield.

\section{REFERENCES}

[1] P. Kumar, G. Rasika, V.Patil, and S. Bobade, "Health Monitoring and Tracking of Soldier Using GPS," International Journal of Research in Advent Technology, vol.2, no.4, pp. 291-294, Apr. 2014.

[2] S. Sharma, S. Kumar, A. Keshari, S. Ahmed, S. Gupta and A. Suri, "A Real Time Autonomous Soldier Health Monitoring and Reporting System Using COTS Available Entities," Second International Conference on Advances in Computing and Communication Engineering (ICACCE), Deharadun-India, May 2015, pp. 683-687.

[3] R. Kumar and M. Rajasekaran, "An IoT based patient monitoring system using raspberry Pi," International Conference on Computing Technologies and Intelligent Data Engineering, Kovilpatti-India,Jan. 2016, pp. 1-4.

[4] R. Shaikh," Real Time Health Monitoring System of Remote Patient Using Arm7,", International Journal of Instrumentation, Control and Automation (IJICA), vol. 1, no. 3-4, pp.102-105, 4, 2012.

[5] D. Kumar and S.Repal, "Real Time Tracking and Health Monitoring of Soldiers using ZigBee Technology: a Survey," International Journal of Innovative Research in Science, Engineering and Technology, vol. 4, no.7, pp. 5561-5574, Jul. 2015.

[6] G. Raj and S. Banu, "GPS Based Soldier Tracking And Health Indication System With Environmental Analysis"International Journal of Enhanced Research in Science 
Technology\& Engineering, vol. 2, no. 12, pp. 46-52, Dec. 2013.

[7] V. Ashok, T. Priyadarshini, and S.Sanjana, "A Secure Freight Tracking System in Rails Using GPS Technology" Second International Conference on Science Technology Engineering and Management (ICONSTEM), Chennai, India Mar. 2016, pp. 47-50.

[8] M..Jassas, A . Abdullah.and H. Mahmoud, "A Smart System Connecting e-Health Sensors and the Cloud" IEEE 28thCanadian Conference on Electrical and Computer Engineering Halifax, Canada, May 2015, pp.712-716. 